\title{
High-Sensitivity Molecular Organometallic Resist for EUV (MORE)
}

\author{
James Passarelli, ${ }^{\mathrm{a}}$ Michael Murphy, ${ }^{\mathrm{a}}$ Ryan Del Re, ${ }^{\mathrm{a}}$ Miriam Sortland, ${ }^{\mathrm{a}}$ Levi Dousharm, ${ }^{\mathrm{a}}$ \\ Michaela Vockenhuber, ${ }^{\mathrm{c}}$ Yasin Ekinci, ${ }^{\mathrm{c}}$ Mark Neisser, ${ }^{\mathrm{d}}$ \\ Daniel A. Freedman ${ }^{\mathrm{b}}$ and Robert L. Brainard ${ }^{\mathrm{a}}$ \\ a College of Nanoscale Science and Engineering, Albany, NY 12203 \\ b State University of New York at New Paltz, New Paltz, NY 12561 \\ c Paul Scherrer Institut, Villigen, Switzerland \\ d Sematech, Albany NY 12203
}

\begin{abstract}
We have developed organometallic carboxylate compounds $\left[\mathrm{R}_{\mathrm{n}} \mathrm{M}\left(\mathrm{O}_{2} \mathrm{CR}\right)_{2}\right]$ capable of acting as negativetone EUV resists. Overall, the best and fastest resists contain antimony, are pentavalent and the carboxylate group contains a polymerizable olefin (e.g. acrylate, methacrylate or styrenecarboxylate). Evidence suggests that high sensitivity is achieved through the polymerization of olefins in the exposed region. We have performed a systematic sensitivity study of molecules of the type $\mathrm{R}_{n} \mathrm{M}\left(\mathrm{O}_{2} \mathrm{CR}\right)_{2}$ where we have studied seven $R$ groups, four main group metals $(M)$, and three polymerizable carboxylate groups $\left(\mathrm{O}_{2} \mathrm{CR}\right.$ '). We found that the greatest predictor of sensitivity of the $\mathrm{R}_{\mathrm{n}} \mathrm{Sb}\left(\mathrm{O}_{2} \mathrm{CR}\right)_{2}$ resists is their level of polymerizable olefins. We mathematically define the polymerizable olefin loading (POL) as the ratio of the number of olefins vs. the number of non-hydrogen atoms. Linear and $\log$ plots of $\mathrm{E}_{\max } v s$. POL for a variety of molecules of the type $\mathrm{R}_{3} \mathrm{Sb}\left(\mathrm{O}_{2} \mathrm{CR}\right)_{2}$ lend insight into the behaviour of these resists.
\end{abstract}

\section{INTRODUCTION}

As the microelectronics industry follows Moore's law, the requirements for photoresists continue to increase. With 16-nm gate-lengths in production, technology capable of supporting the 10-nm lithography node must be developed today. Extreme ultraviolet (EUV, $13.5 \mathrm{~nm}$ ) lithography is thought to be the next imaging technology for fabricating microelectronic devices, but there are still many obstacles that must be overcome. The traditional, chemically-amplified photoresist systems, which have been successful in lithography since the 1980 's are encountering hurdles that are proving difficult ${ }^{1}$ to overcome: poor photon absorption in thin-films, ${ }^{2}$ moderate etch selectivity ${ }^{2,3}$ and limited gains in resolution. ${ }^{4,5}$

Recently, two novel resist systems have been developed based on metal-oxide thin films. ${ }^{6}$ Researchers at Inpria Co., have printed 8-nm dense lines with a dose of $200 \mathrm{~mJ} / \mathrm{cm}^{2}$ using metal-oxide resists. Christopher Ober's group at Cornell has printed $36 \mathrm{~nm}$ dense lines with a dose of $12 \mathrm{~mJ} / \mathrm{cm}^{2}$ using a resist composed of hafnium oxide nano-particles. This pioneering work has demonstrated the great potential of inorganic systems as photoresists.

Here, we present a completely new design for EUV resists based on organometallic carboxylates of maingroup elements. This work is a subset of our group's larger program, Molecular Organometallic Resists for 
EUV (MORE). The MORE approach utilises high EUV optical density metals to increase the photon absorbance of thin resist films. James Thackeray in his 2011 SPIE plenary presentation stated that the target absorption for EUV resist films is 50\%. To print 10-nm lines with an aspect ratio of 2:1, film thickness must be around $20 \mathrm{~nm}$. Polyhydroxystyrene at this thickness will stop only $\sim 10 \%$ of the light $(\mathrm{T} \sim 0.90){ }^{7}$ Loading organic polymers with fluorine will have limited impact. Teflon, which likely contains the most fluorine of any organic polymer, only stops $\sim 30 \%$ of the light in a film of $20 \mathrm{~nm}(\mathrm{~T} \sim 0.70){ }^{7}$ A continuous, $20-\mathrm{nm}$ film of $\mathrm{HfO}_{2}$, on the other hand, will stop $\sim 50 \%$ of the EUV light. ${ }^{7}$

Specifically, we describe a set of organometallic carboxylate MORE resists that have displayed excellent sensitivities. These resist are of the general form $\mathrm{R}_{n} \mathrm{M}\left(\mathrm{O}_{2} \mathrm{CR}^{\prime}\right)_{2}$ where $\mathrm{M}$ is the main-group metal antimony, tin, tellurium or bismuth, and the carboxylate group is capable of undergoing free radical polymerization (acrylate, methacrylate or styrene carboxylate). In this work we explore the systematic variations of the metal $(\mathrm{M})$, the aliphatic or aromatic $\mathrm{R}$ group, and the polymerizable carboxylate group $\left(\mathrm{O}_{2} \mathrm{CR}\right.$ ').

\section{RESULTS AND DISCUSSION}

In designing this resist platform, we sought an EUV free radical photoresist. In this way, one initiation event could lead to multiple solubility-changing polymerization events and yield a negative-tone resist with good sensitivity. Our first attempt at a free radical MORE resist was tri(styrene)antimony (Figure 1A). This molecule can undergo free radical polymerization when heated at $100{ }^{\circ} \mathrm{C}$ and the result is a cross-linked and insoluble network. ${ }^{8}$ When we evaluated tri(styrene)antimony for its EUV sensitivity we found that it was relatively insensitive. The $E_{\max }$, or dose to maximum thickness after development, was $30 \mathrm{~mJ} / \mathrm{cm}^{2}$. We attribute this insensitivity to the relatively high bond dissociation energy of a $\mathrm{Ph}-\mathrm{H}$ bond, ${ }^{9}$ which is often proportional to the organometallic bond strength. ${ }^{10,11}$

While pursuing tri(styrene)antimony, we were concurrently working on antimony organometallic carboxylate molecules like tri(phenyl)antimony diacetate (Figure 1B). This molecule, which does not contain a polymerizable group, demonstrated improved sensitivities over tri(styrene)antimony $\left(E_{\max }=21 \mathrm{~mJ} / \mathrm{cm}^{2}\right)$. We attribute the improvement in sensitivity to the comparatively low bond dissociation energy of carboxylate-peroxides $^{12}$ which is often proportional to organometallic bond strength. ${ }^{10,11}$ Excellent sensitivities $\left(E_{\max }<2 \mathrm{~mJ} / \mathrm{cm}^{2}\right)$ were achieved through the combination of these two previous structural features. Our first molecule of this new class was triphenylantimony diacrylate (JP-20, Figure 1C). This molecule contains both a polymerizable olefin as well as a relatively week antimony-carboxylate bond.

Tri(phenyl)antimony diacrylate (JP-20) has demonstrated remarkable sensitivity characteristics of $\mathrm{E}_{\text {size }}=$ $5.6 \mathrm{~mJ} / \mathrm{cm}^{2}$ for $35 \mathrm{~nm} \mathrm{~L} / \mathrm{S}$ features (Figure 2). Pattern modulation is also shown down to $16 \mathrm{~nm}$ although pattern collapse occurs at these resolutions. This resist has also passed witness plate-based outgassing tests (accumulating $0.98 \mathrm{~nm}$ ) and has excellent shelf-life (no change to NMR of resist in solution for six weeks).

We propose that the sensitivity achieved by this resist is due to the free-radical polymerization of olefins in the exposed regions. We have tested this hypothesis by comparing the sensitivity of triphenylantimony diacrylate (JP-20) to triphenylantimony diacetate (JP-18) as shown in Figure 3. Sensitivity for the 
polymerizable acrylate is more than an order of magnitude greater than the acetate group. Dissolution selectivity and contrast are also improved for the acrylate group. This evidence supports a free radical polymerization mechanism and we are attempting to confirm this through spectroscopic means.

This work details a systematic study of resists of the general form $\mathrm{R}_{\mathrm{n}} \mathrm{M}\left(\mathrm{O}_{2} \mathrm{CR}\right)_{2}$ where the carboxylate group is capable of undergoing free radical polymerization. This is done in three studies (1) metal composition (2) carboxylate composition $-\mathrm{O}_{2} \mathrm{CR}^{\prime}$ and (3) R composition.

A) Tristyreneantimony

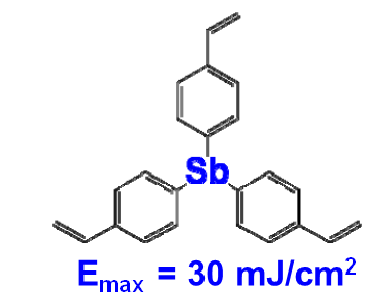

Llterature reports thermal Inltlation of polymerization.
B) Triphenylantimony Diacetate

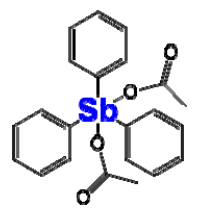

$$
E_{\max }=21 \mathrm{~mJ} / \mathrm{cm}^{2}
$$

Sb carboxylate bonds reported weaker than Sb phenyl bonds.

C) Antimony Acrylate Resists:
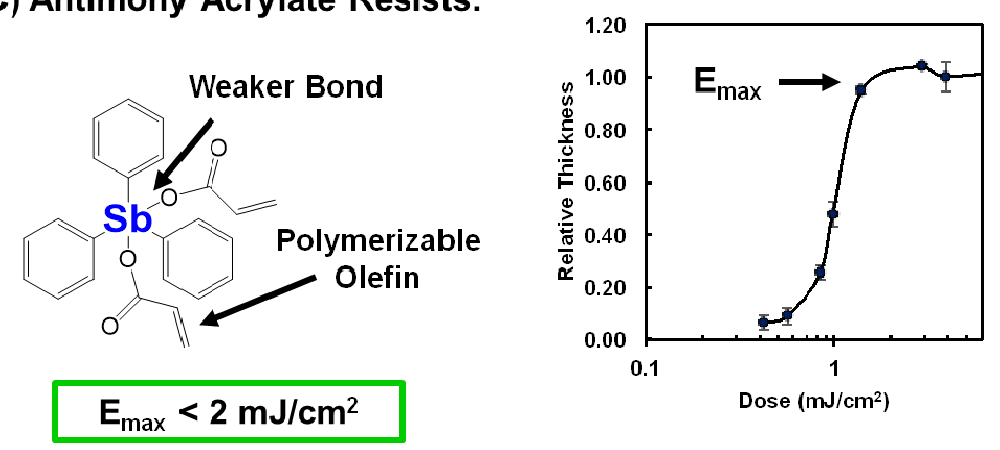

Figure 1. System design of antimony organometallic carboxylate resist platform - JP-20. High sensitivity is achieved through the integration of two resist architectures - one that contains a polymerizable olefin and one that contains a bond that is more readily cleaved by EUV photons. 


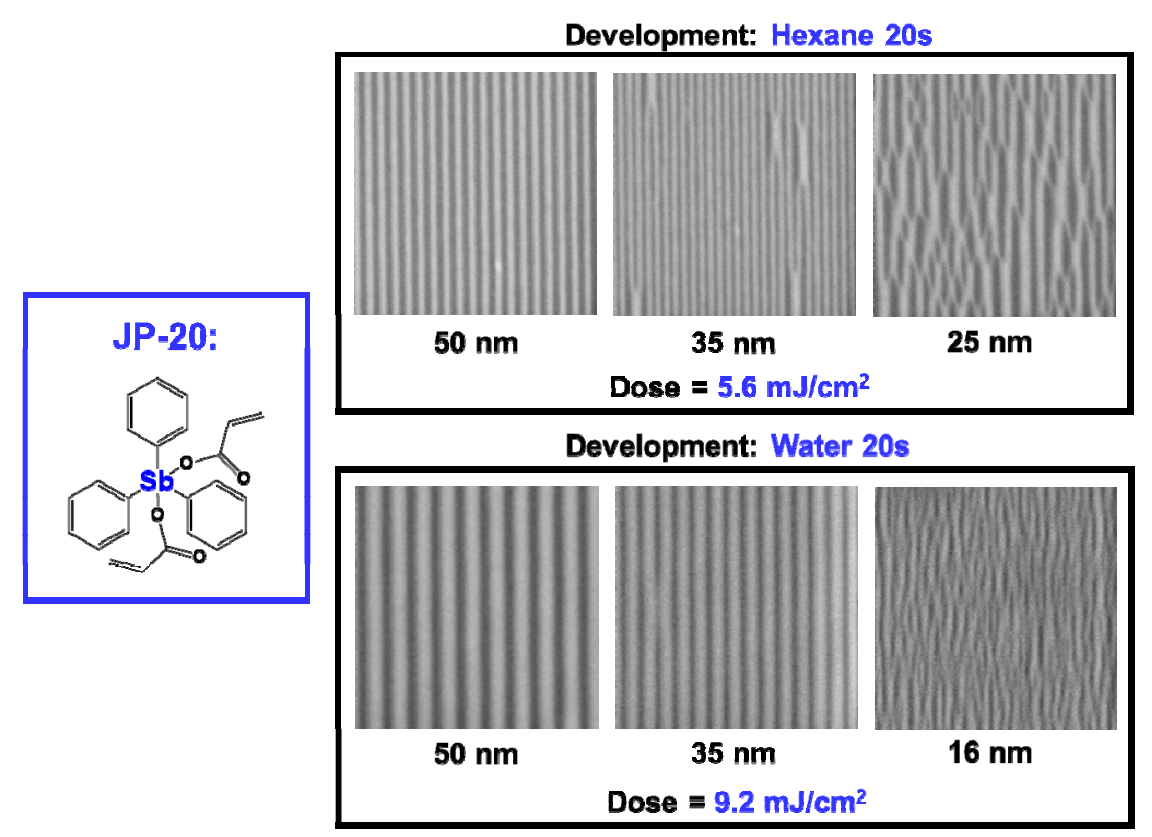

Figure 2. Lithographic performance of JP-20 a representative molecule of this resist platform. High sensitivity at moderate resolutions is demonstrated. Ultimate resolution is limited by pattern collapse.

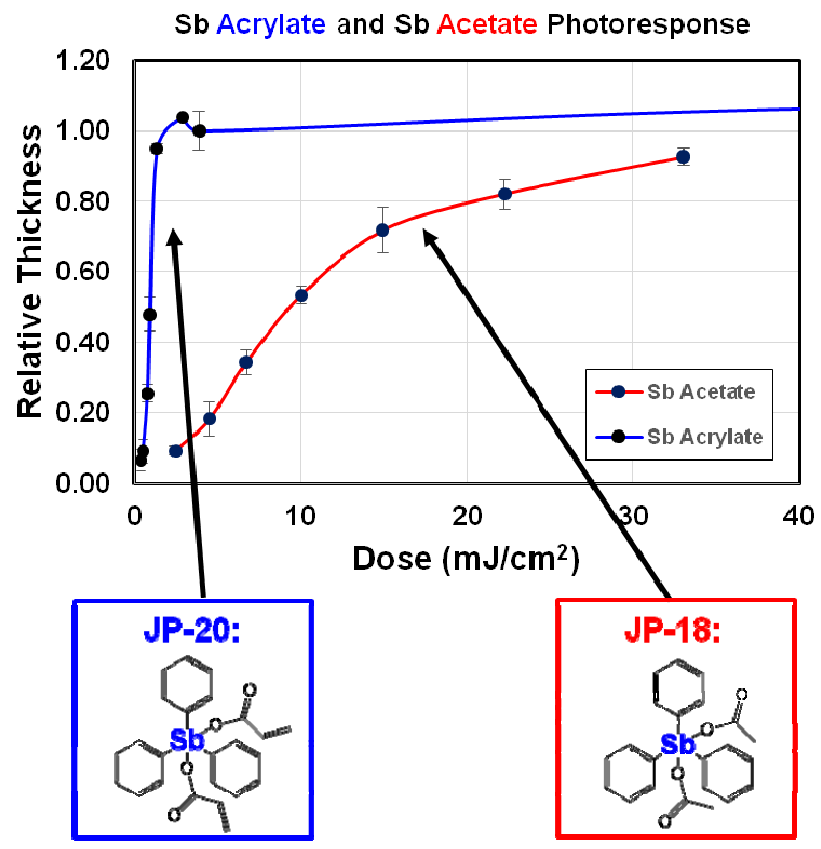

Figure 3. Comparison of MORE resists JP-18 and JP-20. These two resists are comprised of the same metal in the same oxidation state with largely the same chemical substituents. Slight modification between these resists results in dramatic improvement in photo-response. 


\subsection{Effect of Metal Nuclei on $\mathbf{P h}_{\mathbf{n}} \mathbf{M}(\text { Acrylate })_{2}$ on Sensitivity.}

All MORE photoresists contain at least one metal atom with high EUV optical density. The goal of this study is to compare the sensitivity of resists containing antimony, tin, tellurium or bismuth. Molecules of the type $\mathrm{Ph}_{\mathrm{n}} \mathrm{M}$ (acrylate) ${ }_{2}$ were synthesized, coated and evaluated for contrast-curve performance (Figure 4 ). The relative sensitivities are: antimony produces the fastest resist, then bismuth $=$ tin, and tellurium is the slowest. This sensitivity trend cannot be explained by optical density differences since tin and tellurium are about the same and darkest, then antimony, followed by bismuth. The sensitivity of these resists is, therefore, not merely due to their ability to stop photons, but also due to other factors that will be explored in this paper.

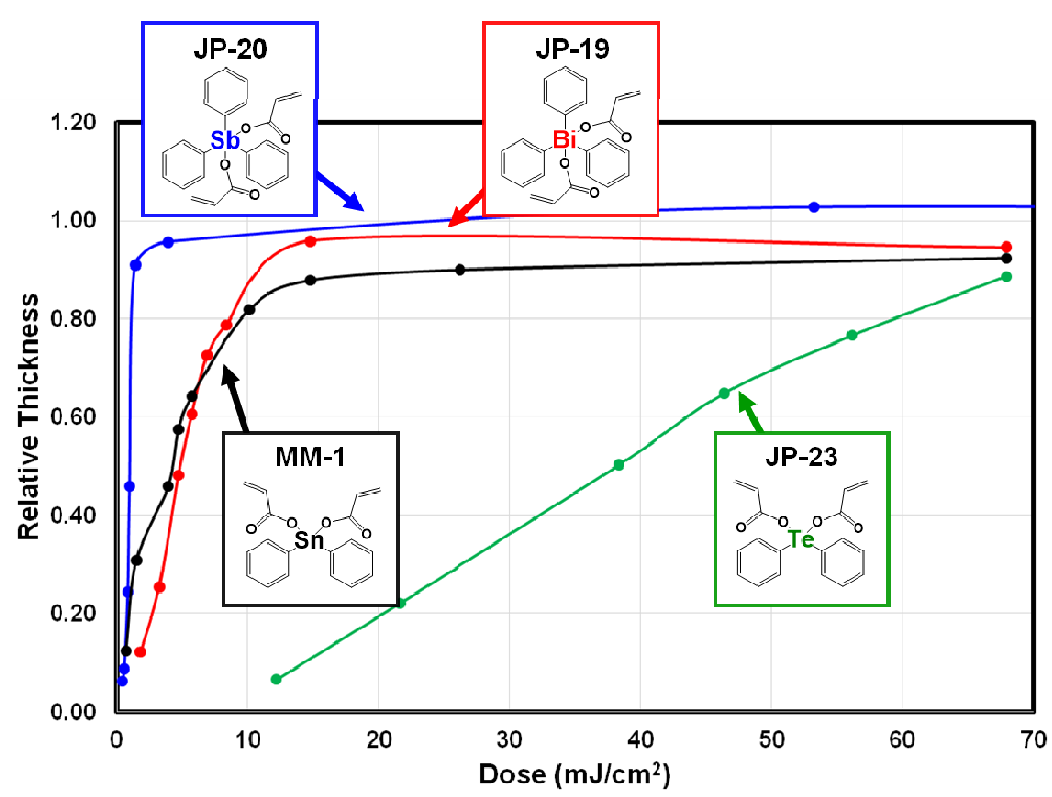

Figure 4. Comparison of $\mathrm{Ph}_{\mathrm{n}} \mathrm{M}(\text { acrylate })_{2}$ where $\mathrm{M}=$ antimony, bismuth, tin or tellurium. Antimony is the most sensitive.

\subsection{Effect of the Polymerizable Carboxylate Group of $\mathrm{Ph}_{3} \mathrm{Sb}\left(\mathrm{O}_{2} \mathrm{CR}\right)_{2}$ on Sensitivity.}

Three typical monomers for free radical polymerization are acrylate, methacrylate and styrene. In order to test the effect of these polymerizable carboxylate groups on sensitivity, we synthesized molecules of the general form $\mathrm{Ph}_{3} \mathrm{Sb}\left(\mathrm{O}_{2} \mathrm{CR}^{\prime}\right)_{2}$ where the carboxylate was acrylate, methacrylate or styrenecarboxylate. These three molecules were also compared to $\mathrm{Ph}_{3} \mathrm{Sb}(\mathrm{OAc})_{2}$ which does not contain a polymerizable group (Figure $5)$.

The acrylate variant is more sensitive than methacrylate, which is more sensitive than styrenecarboxylate. These three polymerizable carboxylates are all more sensitive than $\mathrm{Ph}_{3} \mathrm{Sb}(\mathrm{OAc})_{2}$. This sensitivity trend seems to scale with the molecular weight of the carboxylate group. A possible explanation for this is given section 2.4 .

Lithographic evaluation of the three polymerizable carboxylates is shown in Figure 6. Notice that the dose for Acrylate (JP-20) and Methacrylate (JP-21) derivatives are similar whereas the styrene carboxylate 
(JP-30) is about three times worse. Resolution and overall imaging characteristics for JP-30 are significantly improved over JP-20 and the dose is still respectable.

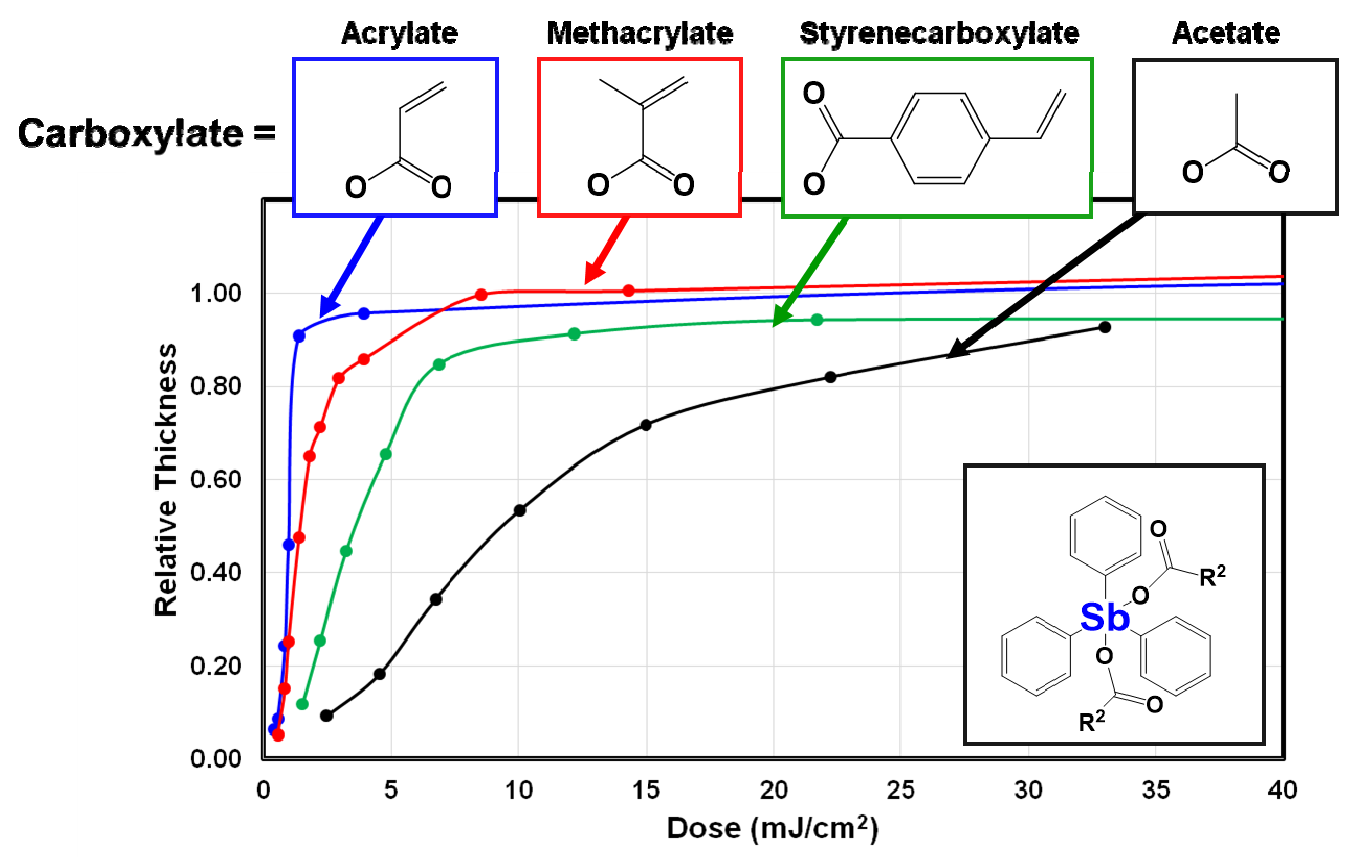

Figure 5. Comparison of the sensitivity of $\mathrm{Ph}_{3} \mathrm{Sb}\left(\mathrm{O}_{2} \mathrm{CR}^{\prime}\right)_{2}$ where the carboxylate is acrylate, methacrylate, styrenecarboxylate or acetate. Acrylate shows the best sensitivity of the four carboxylates evaluated.
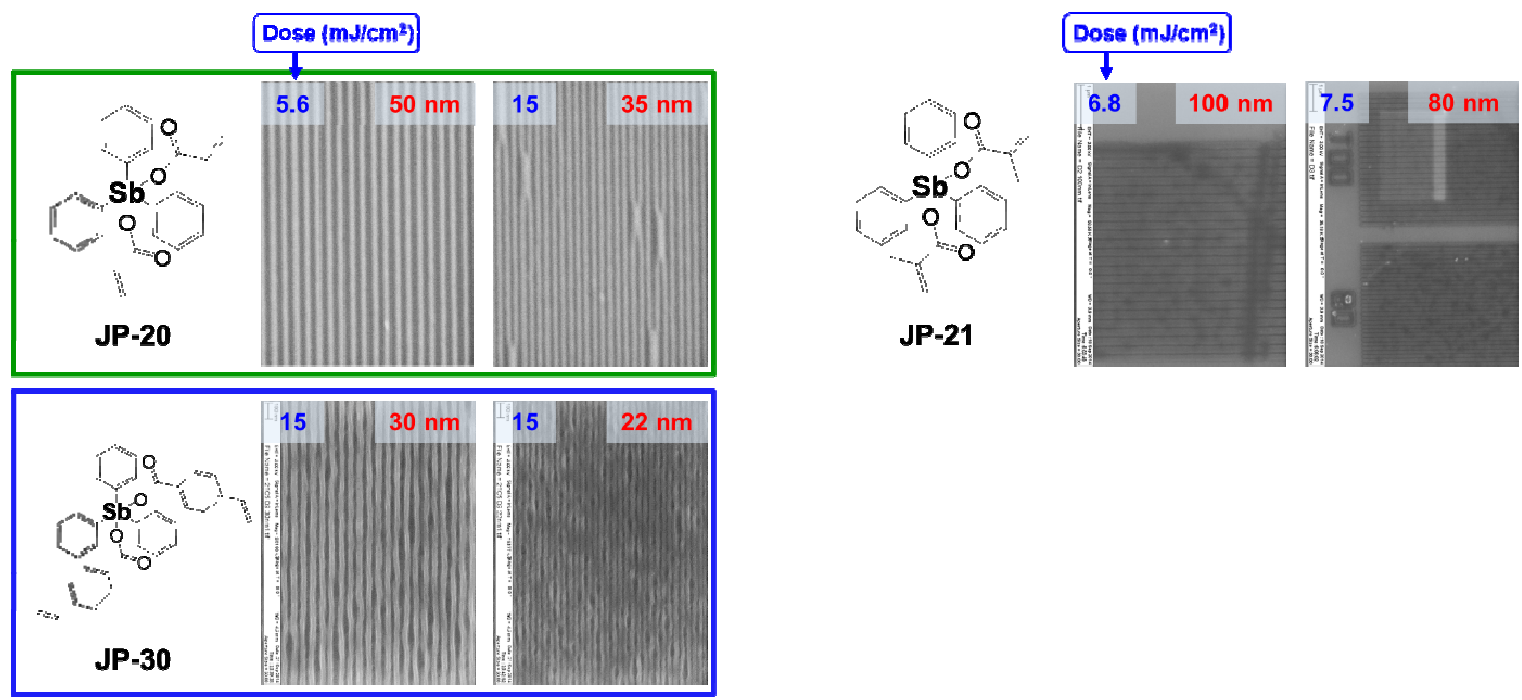

Figure 6. Lithographic evaluation of three antimony organometallic carboxylates of the form $\mathrm{Ph}_{3} \mathrm{Sb}\left(\mathrm{O}_{2} \mathrm{CR}\right)_{2}$. High sensitivity at moderate resolution was demonstrated by JP-20 and good resolution at moderate sensitivity was demonstrated by JP-30. 


\subsection{Effect of the $R$ Group of $\mathrm{R}_{3} \mathrm{Sb}\left(\mathrm{O}_{2} \mathrm{CR}^{\prime}\right)_{2}$ on Sensitivity.}

The last and most extensive of the three molecular studies examines the effect of the hydrocarbon group on resist performance (Figure 7). Notice that these resists are characterized by excellent sensitivity. Several resists are capable of patterning below $30 \mathrm{~nm}$ dense lines although pattern collapse occurs at these dimensions.

In analysis of the lithographic results of this diverse resist set, we have observed trends in SEM stability and observed several unexpected phenomena. These are detailed below in sections 2.3.1 and 2.3.2, respectively.
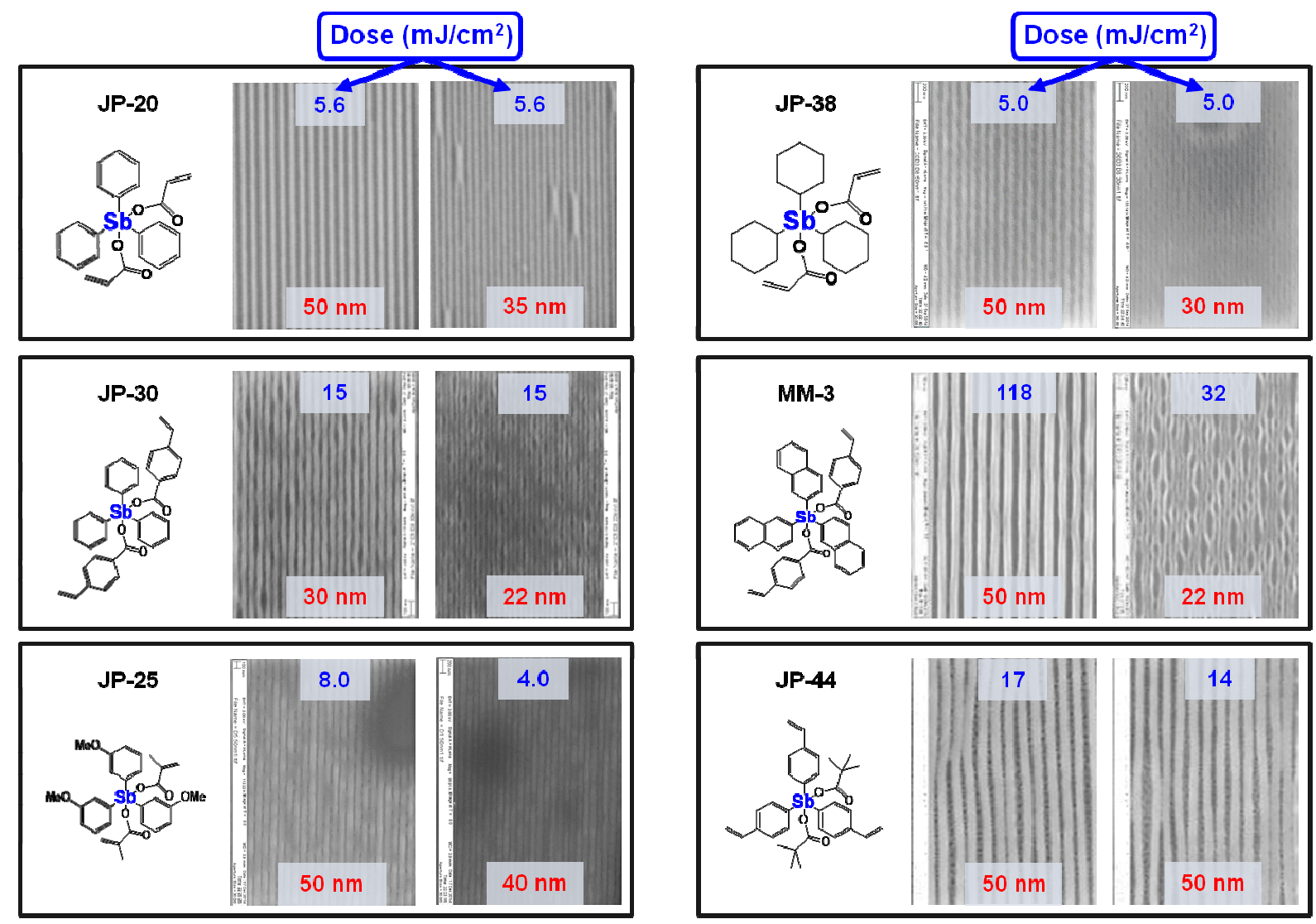

Figure 7. Lithographic summary of six resists with five different $\mathrm{R}$ compositions. All resists attain good sensitivity. Pattern collapse is the current limit to high-resolution imaging.

\subsubsection{Effect of the $R$ Group of $\mathrm{R}_{3} \mathrm{Sb}\left(\mathrm{O}_{2} \mathrm{CR}\right)_{2}$ on Sensitivity - SEM Stability Trends.}

The first antimony organometallic carboxylate molecule of interest, JP-20, displayed poor characteristics while being imaged in an SEM. Patterns could only be visualized when exposed to the SEM's electron beam for short periods. The phenomena, which we call "SEM Instability" is displayed in Figure 8. Notice that pattern modulation is observed in the first scan while no pattern modulation is observed in the second. Our 
current understanding of this phenomenon is that the resist material either ablates or melts due to electron beam energy.

While studying the effect of $\mathrm{R}$ and $\mathrm{O}_{2} \mathrm{CR}$ ' groups on resist performance, we observed that higher molecular weight groups yield improvements in SEM stability. Higher molecular weight $\mathrm{R}$ and $\mathrm{O}_{2} \mathrm{CR}^{\prime}$ groups should have lower volatility than the $\mathrm{R}$ and $\mathrm{O}_{2} \mathrm{CR}$ ' groups of JP-20. A qualitative ordering of the SEM stability of four antimony organometallic carboxylates show that SEM stability increases with increasing molecular weight of the $\mathrm{R}$ and $\mathrm{O}_{2} \mathrm{CR}$ ' groups (Figure 9).
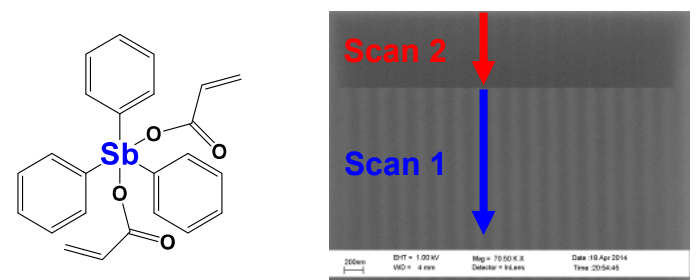

Figure 8. SEM Instability of JP-20. Pattern modulation is displayed in during the first scan of the electron beam. Pattern modulation is not observed during the second. We propose that the resist material is ablated due to electron beam energy or the pattern is melted.

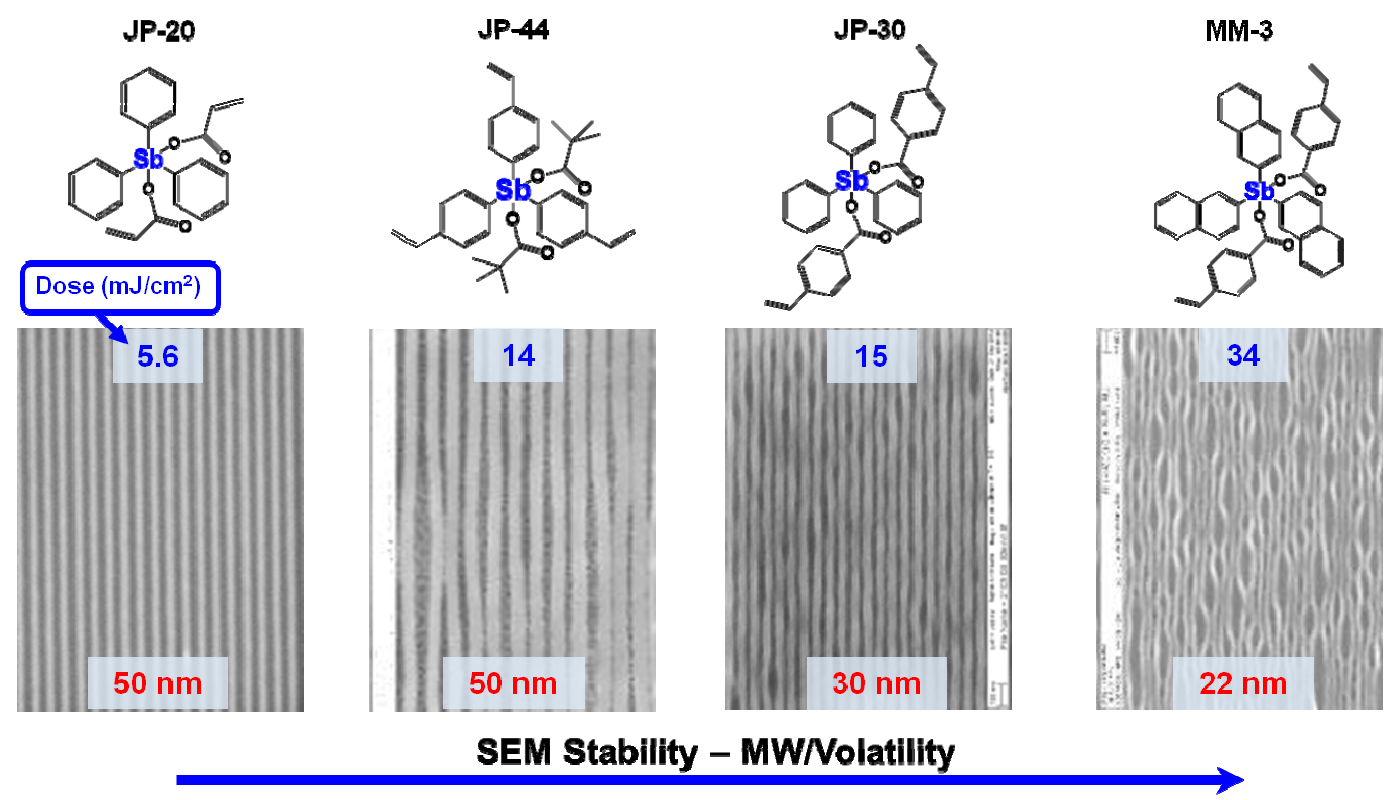

Figure 9. SEM Stability of antimony organometallic carboxylate molecules appears to improve with increases in molecular weight of the $\mathrm{R}$ and $\mathrm{O}_{2} \mathrm{CR}$ ' groups. There is a tradeoff with sensitivity. 


\subsubsection{Effect of Hydrocarbon (R) Identity on Sensitivity - Unexpected Results for $R=$ Cyclohexyl and}

Styrene.

$\mathbf{R}=$ Cyclohexyl. Figure 10 shows a direct comparison of phenyl and cyclohexyl on the lithographic performance of $\mathrm{R}_{3} \mathrm{Sb}\left(\mathrm{O}_{2} \mathrm{CR}\right)_{2}$ resists. Note that tricyclohexylantimony diacrylate (JP-38) shows lithographic performance similar to that of JP-20. This was surprising because of the potential differences in R-Sb bond characteristics for these two molecules. ${ }^{11}$ The similarities between these two molecules occur in the composition of the carboxylate group and that both $\mathrm{R}$ groups are six-carbon cycles. This may point to the role of the R group.

$\mathbf{R}=$ Styrene. In order to increase the density of polymerizable olefins in the resist films, we studied $\mathrm{R}$ groups with polymerizable olefins such as styrene (Figure 11). After our standard development (Hexane 30s), little change was observed in the unexposed region. After very aggressive development, material still remained in the unexposed region. Both development conditions readily clear the unexposed regions of an unexposed wafer. As a result, it appears that a change in solubility occurs in the unexposed regions of LD-1 as a result of the exposure process. Our current hypothesis is that (1) polymerization extended beyond the exposed regions into the unexposed regions and/or (2) the resist is so sensitive that a solubility switch was produced by flare in the exposure chamber. If correct, this phenomena likely results from the high density of polymerizable olefins in a film of LD-1. In this way, once a polymerization event is initiated, it may propagate on a macroscopic length scale before termination. The two unanticipated results given in this section are explored in more detail in section 2.4.

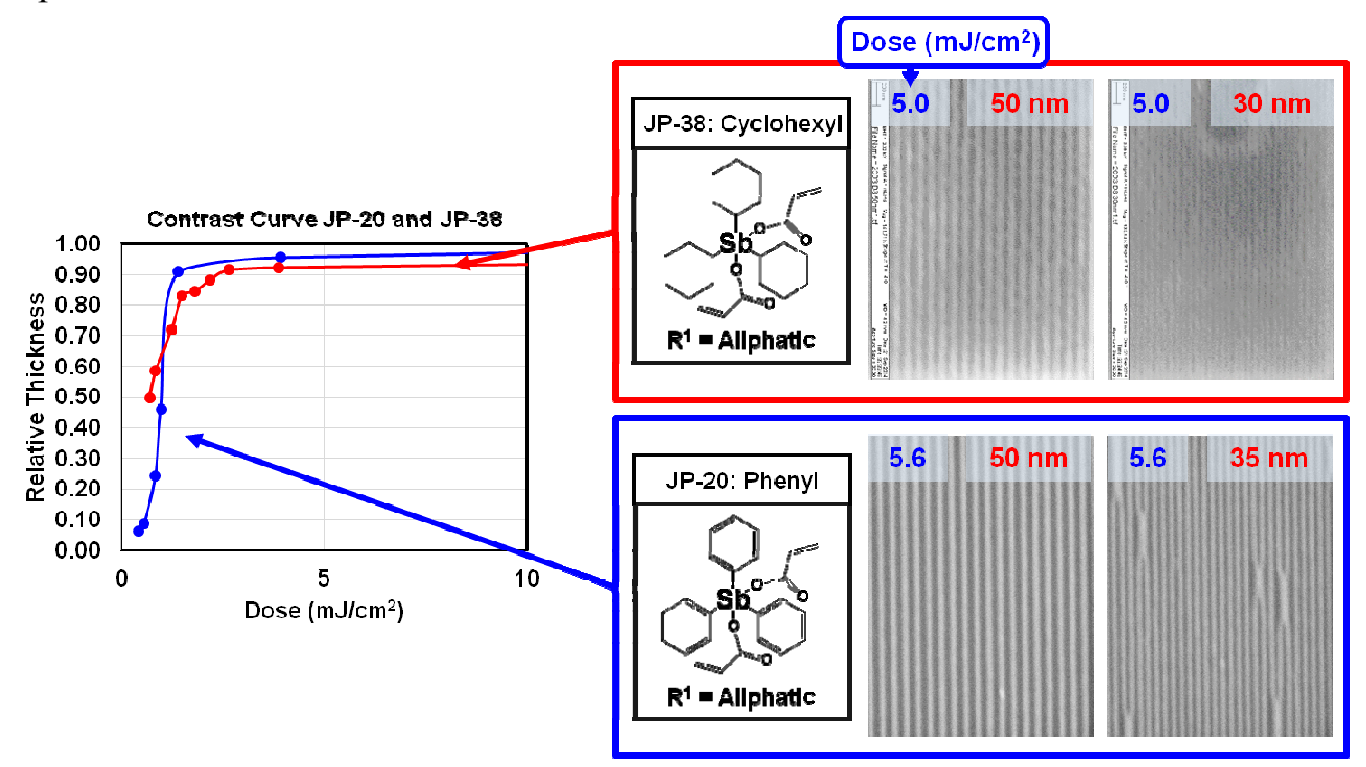

Figure 10. Lithographic results of $\mathrm{R}=$ cyclohexyl. Notice that this molecule displays very similar sensitivity and lithographic results as JP-20. 

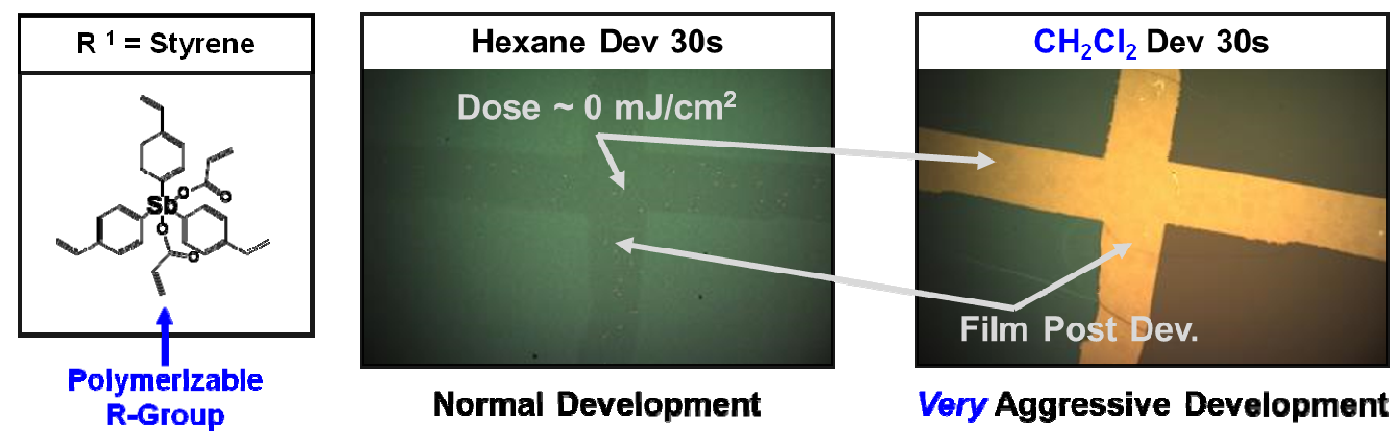

Figure 11. Tristyreneantimony diacrylate (LD-1) has a high density of polymerizable olefins. A solubility shift occurs in the unexposed regions of an exposed wafer. This may be evidence of uncontrolled polymerization propagating to unexposed regions

\subsection{Interpretation of Results.}

The antimony organometallic carboxylate resists demonstrate a considerable departure from traditional polymeric resists. Traditional chemically amplified resists obtain good sensitivity through acid-catalyzed reactions. We propose that antimony organometallic carboxylate resists achieve good sensitivity through the inclusion of polymerizable olefins. In this way, one initiation event may result in the polymerization of multiple olefins and thus multiple solubility changing events (Figure 11). Given the revolutionary nature of this resist system, we must investigate the sensitivity mechanisms in order to understand the capabilities of the system and better target synthesis of new molecules.

In section 2.3.2, we detailed two surprising results. The first is that triphenylantimony diacrylate (JP-20), and tricyclohexylantimony diacrylate (JP-38) display similar lithographic performance despite the antimonyaromatic bond of JP-20 and the antimony-aliphatic bond on JP-38. What is similar in between these two molecules is the ratio of the number of polymerizable olefins to the space filling $\mathrm{R}$ groups. The second surprising result was observed for LD-1 which has a high density of polymerizable olefins as compared to space filling $\mathrm{R}$ groups. This resist demonstrated uncontrolled characteristic where full film thickness was observed in the unexposed region after standard development conditions $\left(\mathrm{E}_{\max } \sim 0 \mathrm{~mJ} / \mathrm{cm}^{2}\right)$.

From these two surprising results, we can develop the hypothesis that the greatest contributor to the sensitivity of molecules of the type $\mathrm{R}_{n} \mathrm{Sb}\left(\mathrm{O}_{2} \mathrm{CR}^{\prime}\right)_{2}$ is the ratio of polymerizable olefins to space filling $\mathrm{R}$ groups. In order to further explore our sensitivity hypothesis, we have defined a hypothetical model for the condensed phase polymerization of $\mathrm{R}_{\mathrm{n}} \mathrm{M}\left(\mathrm{O}_{2} \mathrm{CR}^{\prime}\right)_{2}$ (Figure 12). The $\mathrm{R}$ group in this model act as space filling substituents (red circles) that cannot be superimposed on other $\mathrm{R}$ groups. In order for the propagation of polymerization to occur, the reaction spheres (green circle) of two polymerizable olefins must overlap. Our hypothesis states that the larger the ratio of polymerizable olefins to space filling $\mathrm{R}$ groups, then the larger the turnover number of a given resists. Larger turnover number should lead to greater sensitivity because more molecules are reacted per initiation event, and because higher molecular weight molecules have lower solubility. 
Our proposed sensitivity hypothesis suggests that the sensitivity of these resists should scale with polymerizable olefin loading (POL). A semi-log plot of $\mathrm{E}_{\max } v s$. POL is shown for multiple resist materials (Figure 13). There is a linear relationship between $\log \mathrm{E}_{\max } v s$. POL where as POL increases the $\mathrm{E}_{\max }$ decreases (resist becomes more sensitive). On a linear scale the trend approaches the $\mathrm{X}$ axis at a POL of approximately $9 \%$. This approach corresponds to a POL at which Emax is approaching $0 \mathrm{~mJ} / \mathrm{cm}^{2}$. This sensitivity is consistent with the uncontrolled characteristics of molecules like LD-1 ( $\mathrm{POL}=14 \%$ ).

Further investigation is underway in this area. Understanding of this mechanism should allow better targeting of molecules to improve the lithographic performance of these systems.

Initiation:<smiles>C=CC(=O)O[Sb](OC(=O)COC(=O)c1ccccc1)(c1ccccc1)c1ccccc1</smiles>

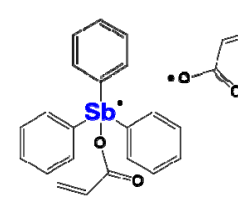

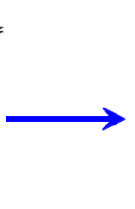

\section{$\mathbf{R}=$ metal or carboxylate- centered radicals}

Propagation:

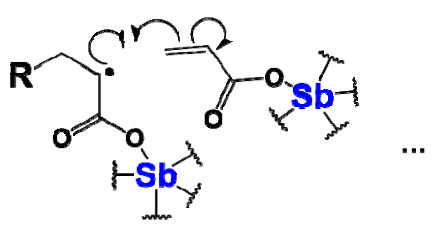

Exposed region crosslinked: less soluble in developer

Figure 11. Proposed mechanism of antimony organometallic carboxylate resist system. We propose that good sensitivity is achieved through one photochemical homolysis event leading to a cascade of subsequent solubility changing polymerization reactions.
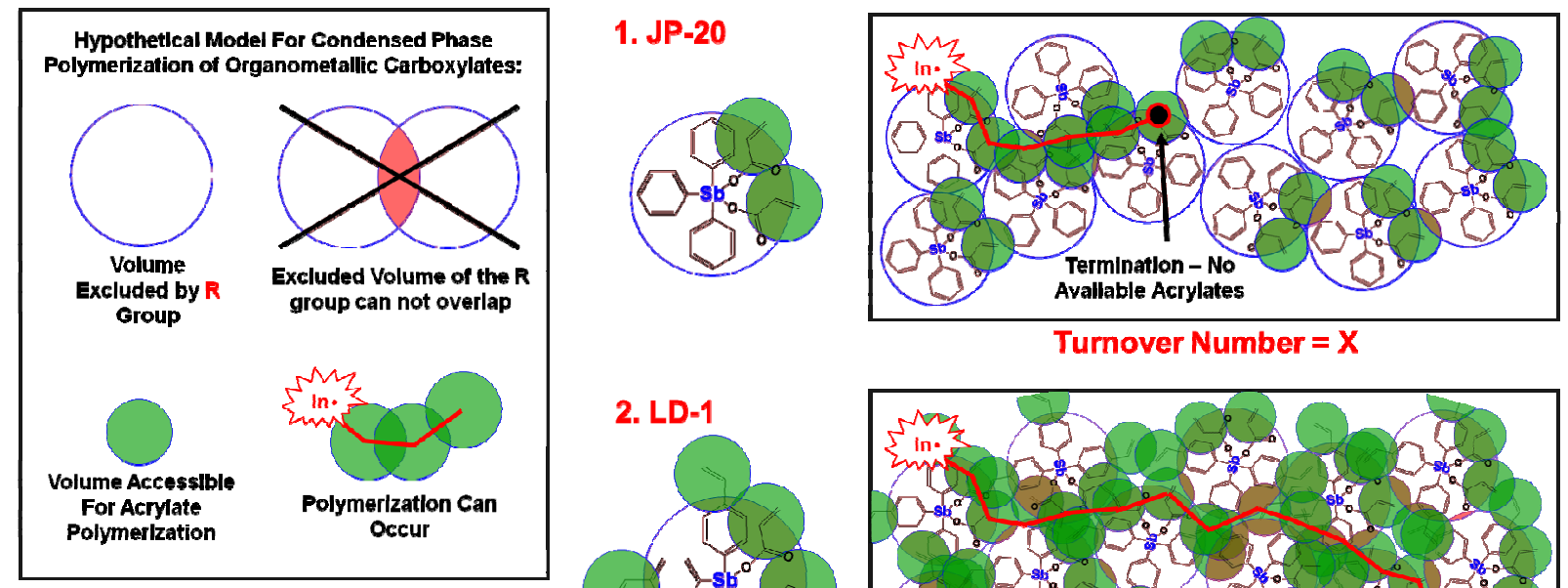

Turnover Number $=\mathbf{X}$
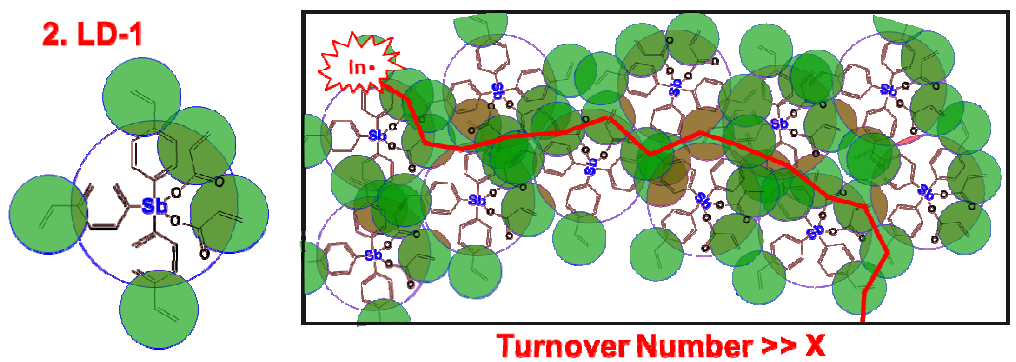

Turnover Number $\gg \mathbf{X}$

Figure 12. Proposed model for condensed phase polymerization of antimony organometallic carboxylate resists. 


$$
P O L=\frac{\# \text { of Polymerizable Olefins }}{\# \text { of Atoms (Excluding Hydrogen })} \times 100 \%
$$

POL: Polymerlzable Olefin Loading

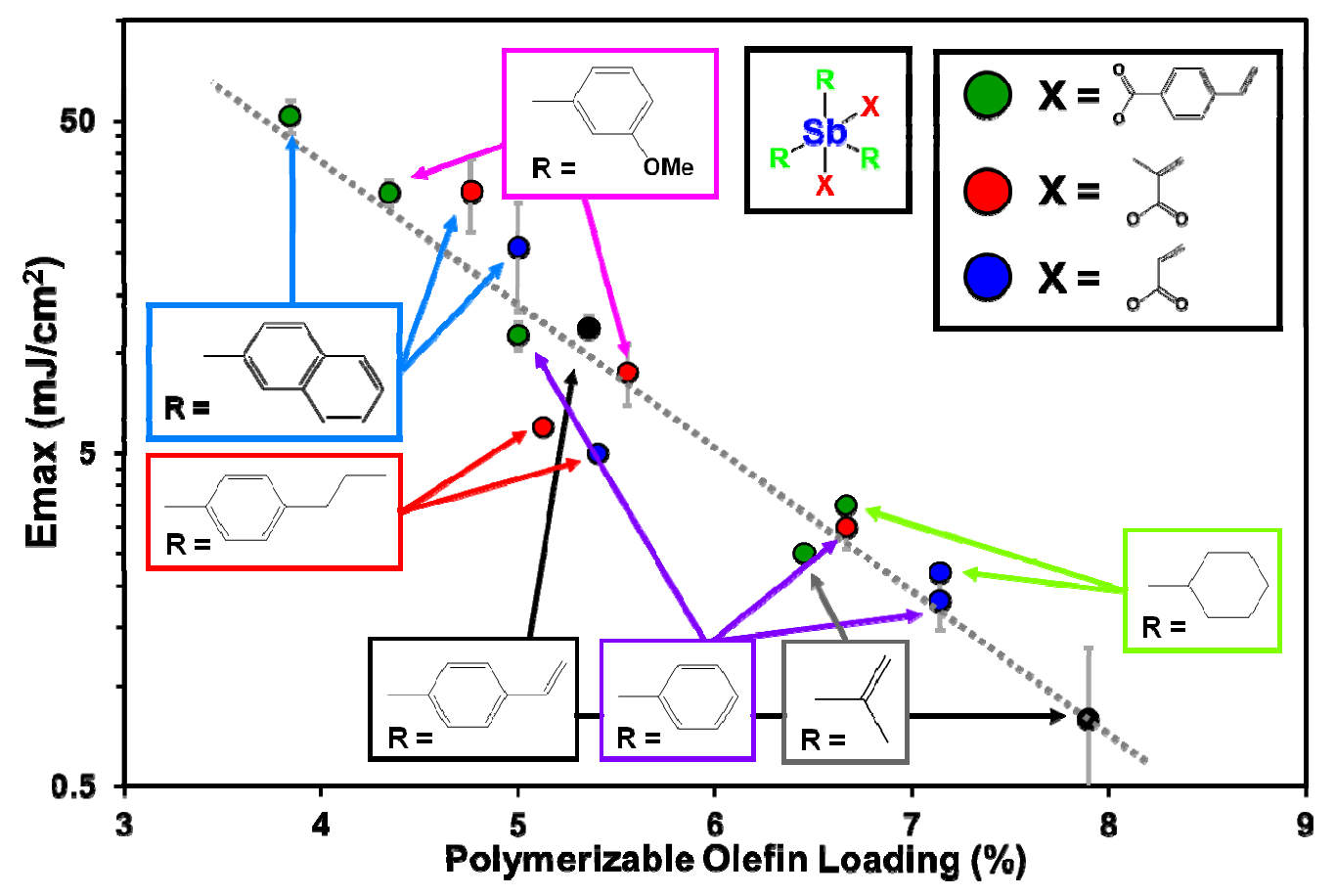

Figure 13. Plot of $\mathrm{E}_{\max } v s$. Polymerizable Olefin Loading (POL). A linear trend is demonstrated between Log $\mathrm{E}_{\max } v s$. POL for multiple antimony organometallic carboxylates.

\section{CONCLUSIONS}

A novel resist system based on organometallic carboxylate molecules with polymerizable olefin substituents has been developed. This system has demonstrated exceptional sensitivity printing $35 \mathrm{~nm}$ dense lines with $5.6 \mathrm{~mJ} / \mathrm{cm}^{2}$. We have studied over 35 molecules of the general form $\mathrm{R}_{\mathrm{n}} \mathrm{M}\left(\mathrm{O}_{2} \mathrm{CR}^{\prime}\right)_{2}$ exhibits variations in $\mathrm{M}, \mathrm{R}$ and $\mathrm{O}_{2} \mathrm{CR}$ '. By comparing molecules of the type $\mathrm{Ph}_{n} \mathrm{M}(\text { acrylate })_{2}$ where $\mathrm{M}=$ antimony, bismuth, tin or tellurium, we found that antimony is the most sensitive and tellurium is the least. By comparing molecules of the type $\mathrm{Ph}_{3} \mathrm{Sb}\left(\mathrm{O}_{2} \mathrm{CR}^{\prime}\right)_{2}$ where the carboxylate is acrylate, methacrylate, styrenecarboxylate or acetate, we found that polymerizable substituents are more sensitive than nonpolymerizable substituents and that sensitivity decreases with increasing carboxylate size. By comparing the sensitivities of molecules of the type $\mathrm{R}_{3} \mathrm{Sb}\left(\mathrm{O}_{2} \mathrm{CR}^{\prime}\right)_{2}$ we have developed the hypothesis that the size of the space filling $\mathrm{R}$ groups as compared to the number of polymerizable olefins contributes most greatly to the sensitivity. We have defined a Polymerizable Olefin Loading (POL), which mathematically relates the number of polymerizable olefins to size of the R groups. We have observed that $\log \mathrm{E}_{\max } v s . \mathrm{POL}$ is a linear relationship where higher POL's lead to more sensitive resists. Our current works aim to (1) spectroscopically confirm the polymerization of olefins upon exposure to EUV and (2) measure the turnover number of resists as a function of POL. 


\section{ACKNOWLEDGEMENTS}

We gratefully acknowledge Sematech for financial support of this work. Part of this work was performed at Swiss Light Source (SLS), PSI, Switzerland. We also thank DuPont and King Industries for supplying materials for our calibration resist and underlayers, respectively.

\section{EXPERIMENTAL METHODS}

General Resist Formulation and Imaging. In general Resist formulations were made by dissolving solids in 1,2-dicloroethane at $1.5 \mathrm{wt} \%$ solids and filtering through a $0.2 \mu \mathrm{m}$ PTFE filter. Formulations were then spincast onto 4-inch silicon wafers, coated with a crosslinked polymeric film (75\% hydroxyethyl methacrylate / 25\% methyl methacrylate copolymers). Resist films were then exposed with 13.5-nm radiation and developed using either DI water or organic developer for 30s. Two exposure tools were used for this study: the Berkeley direct contrast tool (DCT) and the Paul-Scherrer Institut EUV interferometer. ${ }^{6}$

\section{REFERENCES}

[1] G. Moore, Electronics, 1965, 38.

[2] J. Paul, M. Rudolph, S. Riedel, S. Wege, C. Hohle and V. Beyer, The Electrochemical Society Abstract 2012.

[3] J. Paul, M. Rudolph, S. Riedel, X. Thrun, S. Wege and C. Hohle, Advanced Etch Technology for Nanopatterning II, Proceedings from SPIE 2013, 8685.

[4] S. Kang, W. L. Wu, K. W. Choi, A. DeSilva, C. K. Ober and V. M. Prabhu, Macromolecules, 2010, 43, 42754286.

[5] G. P. Patsis, V. Constantoudis and E. Gogolides, Microelectron. Eng., 2004, 75, 297-308.

[6] Y. Ekinci, M. Vockenhuber, M. Hojeij, L. Wang and N. Mojarad, Extreme Ultraviolet Lithography IV, Proceedings from SPIE, 2013, 8679, 867910.

[7] B.L. Henke, E.M. Gullikson, and J.C. Davis. X-ray interactions: photoabsorption, scattering, transmission, and reflection at E=50-30000 eV, Z=1-92, Atomic Data and Nuclear Data Tables Vol. 54 (no.2), 181-342 (July 1993).

[8] M. Koton, and F. Florinskii. Snthesis and polymerization of tris(p-vinylphenyl)antimony and tris(pvinyl)phenylbismuth, Doklady Akademii Nauk, 1966, Vol 169.

[9] S. Blanksby, and B. Ellison. Bond Dissociation Energies of Organic Molecules, Accounts of Chemical Research, 2003, Vol 36.

[10] Haiduc, Ionel, and Jerry J. Zuckerman. Basic Organometallic Chemistry: Containing Comprehensive Bibliography. Berlin: W. De Gruyter, 1985. Print.

[11] Suzuki, Hitomi. Organobismuth Chemistry. Amsterdam: Elsevier Science, 2001. Print.

[12] R. Bach, P. Ayala, and H. Schlegel. A Reassessment of the Bond Dissociation Energies of Peroxides, 1996, Vol 118. 